\title{
Factors Affecting the Adoption of Cloud Computing in Saudi Arabian Universities
}

\author{
Faten Karim ${ }^{1,2}$ \& Giselle Rampersad ${ }^{1}$ \\ ${ }^{1}$ School of Computer Science Engineering and Mathematics, Flinders University, South Australia, Australia \\ ${ }^{2}$ College of Computer Science, Princess Nourah bint Abdulrahman University, Riyadh, Saudi Arabia \\ Correspondence: Faten Karim, School of Computer Science Engineering and Mathematics, Flinders University, \\ South Australia, Australia. E-mail: faten_karime@yahoo.com \\ Received: March 29, 2017 \\ Accepted: April 8, 2017 \\ Online Published: April 30, 2017 \\ doi:10.5539/cis.v10n2p109 \\ URL: http://doi.org/10.5539/cis.v10n2p109
}

\begin{abstract}
Cloud computing is a novel trend in the sphere of information technology. This research sought to identify the factors that could influence the adoption of cloud computing in Saudi Arabian universities, and to comprehend the theories of technology adoption that apply to the uptake of cloud computing in organisations or for individuals, and how they pertained to the study reported here. Four categories of possible influencers were investigated: technological, organisational, environmental, and cultural. This mixed-methods study was based in extended TOE theory (technology, organisation, and environment) and the Hofstede model, which includes cultural factors. To accomplish the goals of the research, an exploratory study consisting of two phases, including qualitative (interviews) and quantitative (survey) was initiated to determine the importance of each of these influencers and the degree of influence. The results revealed that the factors of relative advantage, compatibility, top management support, readiness, competitive pressure, regulatory support, high masculinity, and high individualism have positive impacts on the adoption of cloud computing in this particular context. They also showed that security concerns, high uncertainty avoidance, and high power distance have negative impacts on cloud computing adoption. Unexpectedly, the results indicated that complexity, language and religion do not influence the adoption process.
\end{abstract}

Keywords: cloud computing, higher education, Saudi universities

\section{Introduction}

Cloud computing is the outcome of the development of computer technologies and their combination with the Internet to produce a model for enabling ubiquitous, convenient, on-demand network access to a shared pool of configurable computing resources (e.g., networks, servers, storage, applications, and services) that can be rapidly provisioned and released with minimal management effort or service provider interaction (Mell \& Grance, 2011, p. 2). Many large organisations with extensive IT infrastructures have not been able to benefit from this technology due to quite specific technological, organizational, environmental and cultural limitations. Cloud computing is novel, and consequently there are limited standards or action plans to reduce implementation risks (Jackson 2011) or encourage take-up. Furthermore, there is an absence of exploratory research into the spread and adoption of cloud computing, because of the rapidity of change in this area of technology and organisational responses.

Certainly, very few studies have examined the factors affecting the adoption intention of universities in developing countries, such as Saudi Arabia (Alsanea, 2015; Tashkandi \& Al-Jabri, 2015). Cloud computing usage in Saudi universities has only been considered through the lens of the use of cloud computing in other countries, both developed and developing. There has been a lack of consideration as to whether cloud computing is desired or appropriate in Saudi institutions and culture. Consequently, this study sought to identify for the first time the criteria for successfully adopting cloud computing in tertiary institutions in Saudi Arabia, while also identifying the barriers to its adoption, taking into account the specific needs of the Saudi context, including the wider culture influencing the universities.

The Saudi government has been attempting to update the country's educational systems by adopting the latest and best educational technology practices (Weber, 2011). However, despite its appeal as a cost effective, useful and user-friendly technology, many academic institutions in Saudi have faced major difficulties in their attempts to adopt cloud computing, and there is little in the way of scholarly studies to guide their efforts (Alkhater, Wills, 
\& Walters, 2014), particularly in developing nations. This study is significant therefore for several reasons. Firstly, it helps fulfill Saudi universities' need for a deeper understanding of the factors that affect the adoption of cloud computing. Secondly, it fills the gap in practical studies related to the Saudi higher education sector. Thirdly, from a theoretical perspective, it examines cloud technology adoption at the organisational level. Lastly, this study is significant since it adds to the existing knowledge in this domain, adding insight into the distinctive cultural context of Saudi Arabia.

Furthermore, this study contributes to the existing literature in the field of cloud computing and technology adoption in Saudi Arabian higher education institutions by (a) extending the TOE framework to the study of cloud computing adoption, (b) developing a validated conceptual model for inspecting the critical factors related to adopting cloud computing in Saudi universities.

\section{Theoretical Background}

\subsection{Existing Theories on Technology Adoption}

Various theories of technology adoption exist at both the individual and organizational levels. Theories at the individual level describe the ways in which individuals approach technology, why they adopt it or reject it, and when or in what circumstances. This model of technology adoption shows that adoption is influenced by personal beliefs, attitudes, and intentions, and a variety of well-known theories exist to explain the ways in which individuals interact with technology: the theory of reasoned action (TRA) (Fishbein \& Ajzen, 1975); the theory of planned behaviour (TPB) (Ajzen, 1991); the technology acceptance model (TAM) (Davis, 1989); and the unified theory of acceptance and use of technology (UTAUT) (Venkatesh, Morris, Davis, \& Davis, 2003). In adopting IT, these theories relate to individuals' choices, and not the role played by organisational and environmental features.

Prominent theories of adoption of technology at the organisational level include the: diffusion of innovation (DOI) (Rogers Everett, 1995); resource-based theory (RBT) (Barney, 1986); and technology-organisation-environment framework (TOE) (Tornatzky \& Fleischer, 1990).

\subsection{Technology-Organisation-Environment Frameworks (TOE)}

The technological component of the TOE framework consists of internal and external technologies pertinent to the organisation. These may be existing technologies and/or the technology to be implemented. This implementation process is affected by the context surrounding the technological features (Chau \& Tam, 1997; Tornatzky \& Fleischer, 1990).

The context of the organisation consists of the organisational features that may obstruct or encourage the adoption process. Examples of these features include the organisation's size and structure, support at the level of management, and the human resource attributes (Yoon, 2009). Organisations with supporting regulations and skilled human resources are more equipped to successfully adopt technology. Well-trained senior managers are the most qualified to overcome obstacles to the adoption of technology within an organisation.

The organisational environment also consists of the organisation's commerce, competitors, and governmental policy or intention (Low, Chen, \& Wu, 2011). These factors can either promote or impede the uptake of technology. In addition, strong competition inspires organisations to pursue aggressive technological policies and can motivate the rapid spread of new technology across firms (Kuan \& Chau, 2001).

\subsection{The Influence of National Culture}

Culture and technology are interdependent. The former regulates the latter and is a determining factor in the systems of interaction in any society (Straub et al., 2003). Roseman, Dhawan, Rettek, Naidu, and Thapa (1995) describe culture as a way of life of a people; while Hofstede and Minkov (1991, p. 5) define national culture as 'the collective programming of the mind which distinguishes the members in one human group from another'. Research is lacking on the influence of culture on cloud computing adoption in Saudi. The need to examine the role of the national culture as one of the facets that may influence the adoption of cloud computing in Arab nations such as Saudi Arabia remains clear. Hofstede's definition of a cultural dimension model, being widely recognised and accepted, has been chosen in this research as a theoretical framework to assess the significance of national culture on cloud computing adoption in Saudi Arabia.

\section{Development of the Conceptual Model}

\subsection{The Conceptual Model}

The constructs forming the conceptual model for the study were: relative advantage, compatibility, security concerns, complexity, top management support, readiness, competitive pressure, regulatory support, 
individualism-collectivism, power distance, uncertainty avoidance, and masculinity-femininity.

These factors were taken from the literature, and used to interpret the adoption or non-adoption of technology. Figure1 shows the proposed model for investigating cloud computing adoption in Saudi universities, and demonstrates the dependent and independent variables' relationships. In order to provide a comprehensive framework for the study of cloud computing adoption in Saudi universities, two diverse components (TOE theory and Hofstede framework) were combined to form the proposed conceptual model. Validity was verified by analysing the data collected during fieldwork.

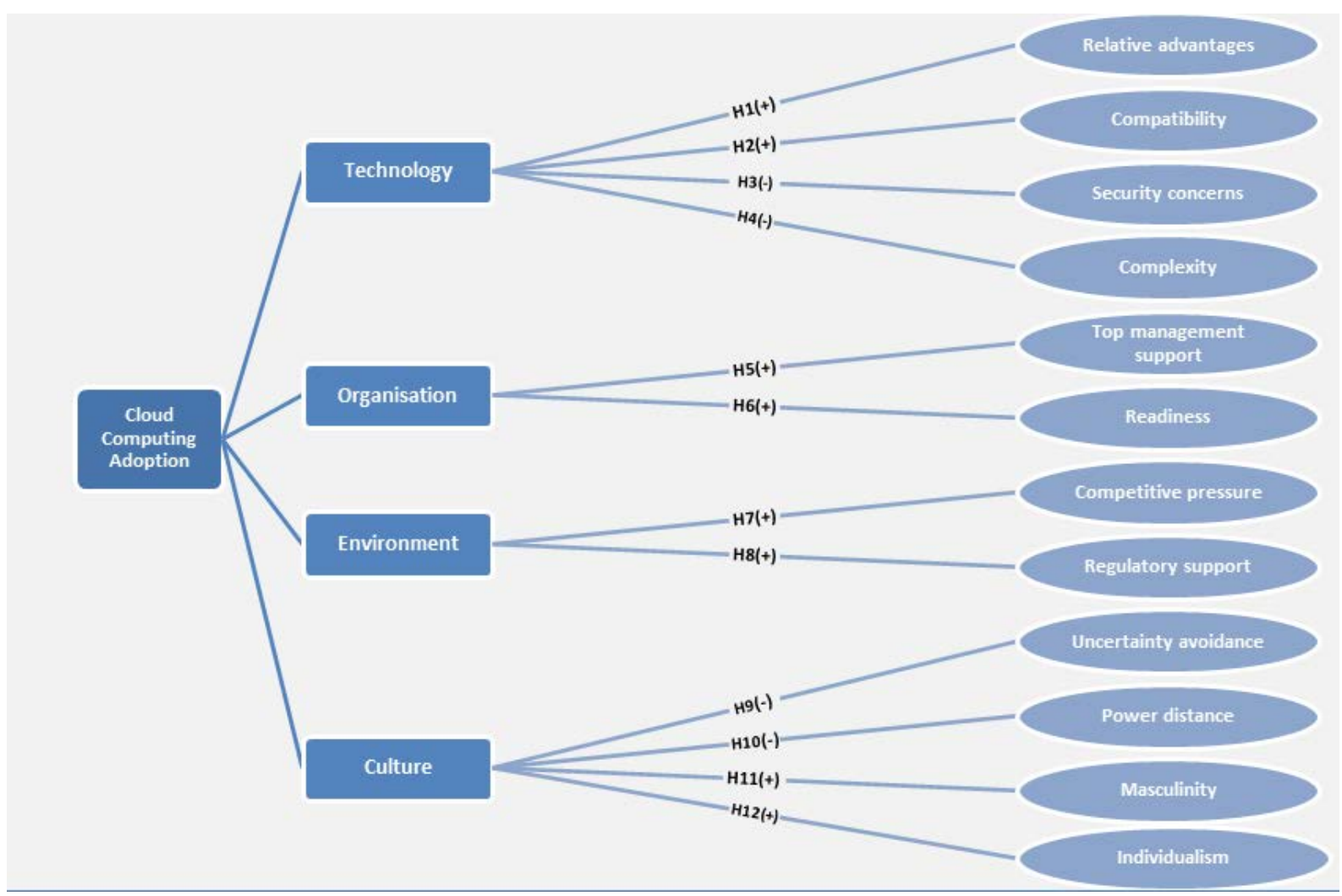

Figure 1. The proposed conceptual model

\subsection{Study Hypotheses}

\subsubsection{Technology Factors}

Relative advantage. Relative advantage is a term encapsulating the idea that benefits accrue to an organisation when it adopts a particular technology that gives it a competitive edge or advantage within its sphere of operation (Rogers, 2010). The adoption of cloud computing has the potential to deliver a relative advantage to a uni versity in a developing sector. In this study, relative advantage denotes a decline in administration requirements, reorganized IT systems, reduced maintenance efforts, reduced software costs, and increased flexibility of computing resources because simplifying or reducing the costs of all of these features would improve the administration of a university relative to others in the sector.

Participants in the current study were interviewed about what they expected from cloud computing. The responses were categorised, discarded and reinforced by references from the literature, and the following hypothesis proposed:

Hypothesis 1: The relative advantages of cloud computing positively influence the intention to adopt cloud computing.

Compatibility. Compatibility is the extent to which the technology is suited to an organisation's existing normed occurrences and practices (Rogers Everett, 1995). Grandon and Pearson (2004) and Thatcher, Foster, and Zhu (2006) have argued that compatibility is the strongest driver for the adoption of technology when compared to other innovative features. Thus, it was hypothesized that:

Hypothesis 2: Compatibility positively influences the intention to adopt cloud computing. 
Complexity. According to Rogers (2010, p. 229), complexity is the 'the degree to which an innovation is perceived to be relatively difficult to understand and use'. Therefore, the likelihood of adoption is increased if the technology is regarded as relatively straightforward by the intended users. Preceding studies, such as those of Kwon and Zmud (1987) and Tornatzky and Fleischer (1990) have also indicated that complexity has a negative impact on the adoption of innovative technology. In conclusion, relative complexity is an important driver in the acceptance of cloud technology. The following conclusion could therefore be made:

Hypothesis 3: Complexity negatively influences the intention to adopt cloud computing.

Security. Security risks require careful consideration by organisations contemplating cloud computing (Carroll et al., 2011). Concerns around cloud computing security are well-founded, given the intersection of storage and computing in multi-user environments like a cloud computer system (Schneiderman, 2011; Wu, Shen, Wang, Zhu, \& Zhang, 2011).

Ogigău-Neamţiu (2012) have argued that to help reduce threats, cloud computing stakeholders should invest in security implementation measures to ensure data is kept protected and private at all times; but concern that security cannot be achieved might cause organisational managers to resist the adoption of cloud computing by organisations. Hence:

Hypothesis 4: Security concerns negatively influence the intention to adopt cloud computing.

\subsubsection{Organisational Factors}

Senior management support. Since cloud computing involves resource allocation, services integration and procedures reengineering, the role of senior management is critical in the implementation process (T. Wang \& Lai, 2014) since senior managers have the power to influence organisational members. When the benefits of cloud computing are acknowledged, comprehended, and consented to, the resources necessary to enable implementation will be provided, fostering smoother and more efficient adoption. Failure on the part of senior management to comprehend or to accept the benefits of cloud computing can result in opposition to the adoption process, and failure of the project (Altameem, 2007). Altshuler and Zegans (1990) found that innovative organisations display the desire to support the change to a new technology by spending time and effort motivating employees. Thus:

Hypothesis 5: Senior management support positively influences the intention to adopt cloud computing.

Readiness. Organisational readiness is determined by the state of technological readiness within the organisation itself (Duan, 2012). Enhanced technological readiness involves both structural features and specialised human resources. The structural features are the technological infrastructure already in place within the firm, such as network technologies and enterprise systems. Those within the organisation with the mastery and expertise to put cloud computing into action are considered the specialised human resources (e.g., personnel with computer knowledge, IT specialists) (Lee, Wang, Lim, \& Peng, 2009). Organisations with a high level of technological readiness are generally more suited for the adoption of cloud computing. Consequently:

Hypothesis 6: Organisational readiness positively influences the intention to adopt cloud computing.

\subsubsection{Environmental Factors}

Competitive pressure. Competitive pressure describes the degree of exertion brought to bear upon an organisation by adversaries from within the industry (Zhu \& Kraemer, 2002). It has long been recognised as a significant driver of technology diffusion. Ross (2010) argues that as a consequence of the high rate of technological change in business in general, it can be anticipated that an organisation's expectation for cloud computing will be that it will happen.

Adopting new technology is oftentimes a strategic essential when competing in the market, and Ross (2010) suggests that, consequent to rapidly changing technology, organisations will require cloud computing to satisfy their ongoing technological needs.

Hypothesis 7: Competitive pressure positively influences the intention to adopt cloud computing

Regulatory support. Regulatory support is provided by governments to promote IT adoption by firms (Thatcher et al., 2006). Regulations and laws can be crucial in the adoption of new technologies. The power and the willingness of governments to foster institutional environments that encourage private investment and activity is critical to the adoption of innovative technology (Oxley \& Yeung, 2001; Thatcher et al., 2006). Shore (2001) advocates that governments back the adoption of IT visibly via national incentives for training and sustaining an appropriate IT workforce. Sustained government support that includes the conscientious regulation of ITC is a significant factor in IT adoption (i.e. Internet, e-commerce) (L. Chang et al., 2001; Grandon \& Pearson, 2004; 
Hamad, 2014; Kuan \& Chau, 2001). Therefore:

Hypothesis 8: Government support of a fair regulatory environment positively influences the intention to adopt cloud computing.

\subsubsection{Cultural Factors}

Uncertainty avoi dance. Hofstede (2001, p. 148) specifically points out that 'uncertainty avoidance is not the same as risk avoidance' and explains, '... uncertainty is to risk as anxiety is to fear.' It was found that uncertainty avoidance is a significant factor in determining the adoption of ICT because of the perception of risk. Those who are uncomfortable with uncertainty can be expected to avoid experiencing new technologies, such as cloud computing (Leidner \& Kayworth, 2006).

Uncertainty among individuals is common, and may cause dilemmas for businesses new to cloud computing in the Arab world (Zhao, Scheruhn, \& von Rosing, 2014). The following hypothesis is hence suggested:

Hypothesis 9: High uncertainty avoidance negatively influences the intention to adopt cloud computing.

Power distance. The degree to which less powerful people accept that power is divided unevenly is called power distance. In the Arab community, power distance is high. People in this world region expect that their leaders will distance themselves from the general population. Unequal power and influence are expected and accepted. Hofstede (1991) suggests that in countries within which organisational structures exhibit a high power distance, there is a structure of centralised decision making, authoritarian control, and formalised rules. Adopting cloud computing may limit managerial dominance of such an organisation (Al-Sukkar, 2005).

The following hypothesis is suggested:

Hypothesis 10: High power distance negatively influences the intention to adopt cloud computing.

Masculinity (MAS). Hofstede notes that gender distinction is the result of the biological differences between males and females. Culture could be deemed masculine or feminine depending on how a society defines and follows social standards. Hofstede's survey demonstrates two basic facts. Firstly, historically, masculine cultures tend to be more militaristic and competitive, whereas feminine cultures prompt enhanced cooperation. Secondly, masculine cultures emphasise ambition, competitiveness, and material values. Thus, to stay ahead of the competition, organisations with higher MAS scores are inclined to adopt new technologies (Zhao et al., 2014). Hence, the following is hypothesised:

Hypothesis 11: High masculinity positively influences the intention to adopt cloud computing.

Individualism - collectivism. Individualism is the lowest Hofstede dimension in the Arab world, which indicates that people in the region place importance on groups and families, i.e., their culture values collectivism. American culture, on the other hand, demonstrates a great degree of individualism (Al-Sukkar, 2005). In organisations with a highly individualistic culture, employees are more autonomous (Zhao et al., 2014), following their own pace and schedule in completing business processes and tasks. The autonomy provided by cloud computing appeals to highly individualistic cultures. The following hypothesis is then suggested:

Hypothesis 12: High individualism positively influences the intention to adopt cloud computing.

\section{Research Methods}

In this research, qualitative and quantitative methods complemented each other, i.e., this was a multi-method research study. In stage one, the qualitative approach was used to generate data from the interviewees, such as their perceptions of barriers and the current attitudes in their institutions in relation to technology, as well as the level of usage of IT. The results of the qualitative research were used to build theories for further testing using quantitative methods (Aaker, Kumar, \& Day, 2008; Creswell \& Clark, 2007). The TOE and Hofstede theories, combined with the language and religion factor, incorporated all the factors derived from the literature review and any emerging from the interviews.

Qualitative research. Qualitative research explores the variables under investigation, in this instance through in depth semi-structured interviews. The interviews were conducted at PNU, and the analysis of the data followed a thematic process. Data generated by the interviews were coded (Table 1) and analysed using the input from themes that had emerged from the literature (Boyatzis, 1998). The conceptual model of this research was the foundation for designing the interview questions. All collected data from the interviews were classified and identified for placement in the refined proposed model. 
Table 1. A priori codes for use in data analysis

\begin{tabular}{lllll}
\hline Themes & Technological & Organisational & Environmental & Cultural \\
\cline { 1 - 3 } & Relative advantage & Top management support & Competitive pressure & Uncertainty avoidance \\
& Compatibility & Readiness & Regulatory support & Power distance \\
& Security concerns & & & Masculinity \\
\multirow{0}{0}{} & Complexity & & & Individualism \\
\hline
\end{tabular}

Quantitative research. The purpose of the quantitative stage was to test and validate the refined proposed model that had emerged from the qualitative stage of the research. A reliable survey instrument was developed following the validating paradigms presented by Churchill Jr (1979) and Straub, Boudreau and Gefen (2004). The survey instrument procedure thus consisted of two main processes - survey instrument development and refinement.

Survey instrument development entailed the construct's domain specification and the individual construct's item generation (Churchill Jr, 1979; Straub et al., 2004). The construct's domain specification was completed by extensively reviewing the literature on cloud computing and the adoption of technology in universities.

Survey instrument refinement. A pre-test was employed to check the survey instrument. Content and face validity were assessed at the pre-test (Hair et al., 2010; Saunders, 2004). In this study the content validity of the survey instrument was assessed using the expertise of three officials well versed in instructional technology (IT) working in different Saudi universities. To achieve face validity for the questionnaire for this study, the expertise of two Computer Science School PhD students was employed on the first draft to assess the comprehension of each item. The resulting feedback noted questionnaire length and ambiguous items. Structural equation modelling (SEM) was used to analyse the data because it is a very useful way to test theories. It enables researchers to test whether latent variables in a pre-specified hypothesised theoretical model are related to each other (Hair et al., 2010). Prior to conducting these multivariate statistical analyses, examination of the data and scale reliability were conducted, the purpose being to determine if they met the basic assumptions required for further analysis. This study used Cronbach's alpha, a measure of reliability that provided an indication of the consistency of the responses across items.

\section{Qualitative and Quantitative Results}

\subsection{Emergence of New Factors}

New factors emerged during the interviews that were important to the interviewees, and the researcher considered them worth adding to the conceptual model. The new factors were language and religion, which were highlighted in the literature as significant in cultural contexts. They were added to the cultural context of the refined conceptual (Figure 2) model and the following hypothesis was added to the research hypotheses:

Hypothesis 13: Language and religion negatively influences the intention to adopt cloud computing.

The literature supported the observation that language is an important obstacle to IT diffusion, especially in developing countries. Al-Gahtani, Hubona, and Wang (2007) and Vatanasakdakul, Tibben, and Cooper (2004) have pointed out that amongst many barriers to IT diffusion in developing countries, language disparity can be ranked as one of the most severe. English was the predominant language in the development of IT and in the continues to dominate the ongoing development of new technology in the IT field, . and English is consequently the principle language used on the Web (Chieochan, Lindley, \& Dunn, 2002; Perry \& Schneider, 2000).

Regarding religion, Slowikowski and Jarratt (1997) have pointed out that cultural factors, specifically, 'traditions', 'religion' and 'fatality' play important roles in the adoption of innovation. Religion is a critical cultural element, and a convincing identifier in global, as well as regional geopolitical conflicts (Tanasyuk \& Avgerou, 2009). Furthermore, as Hill, Loch, Straub, and El-Sheshai (1998) state, religion plays an important role in Arab lives. Religion affords the foundation for their beliefs and ethical restraints. 


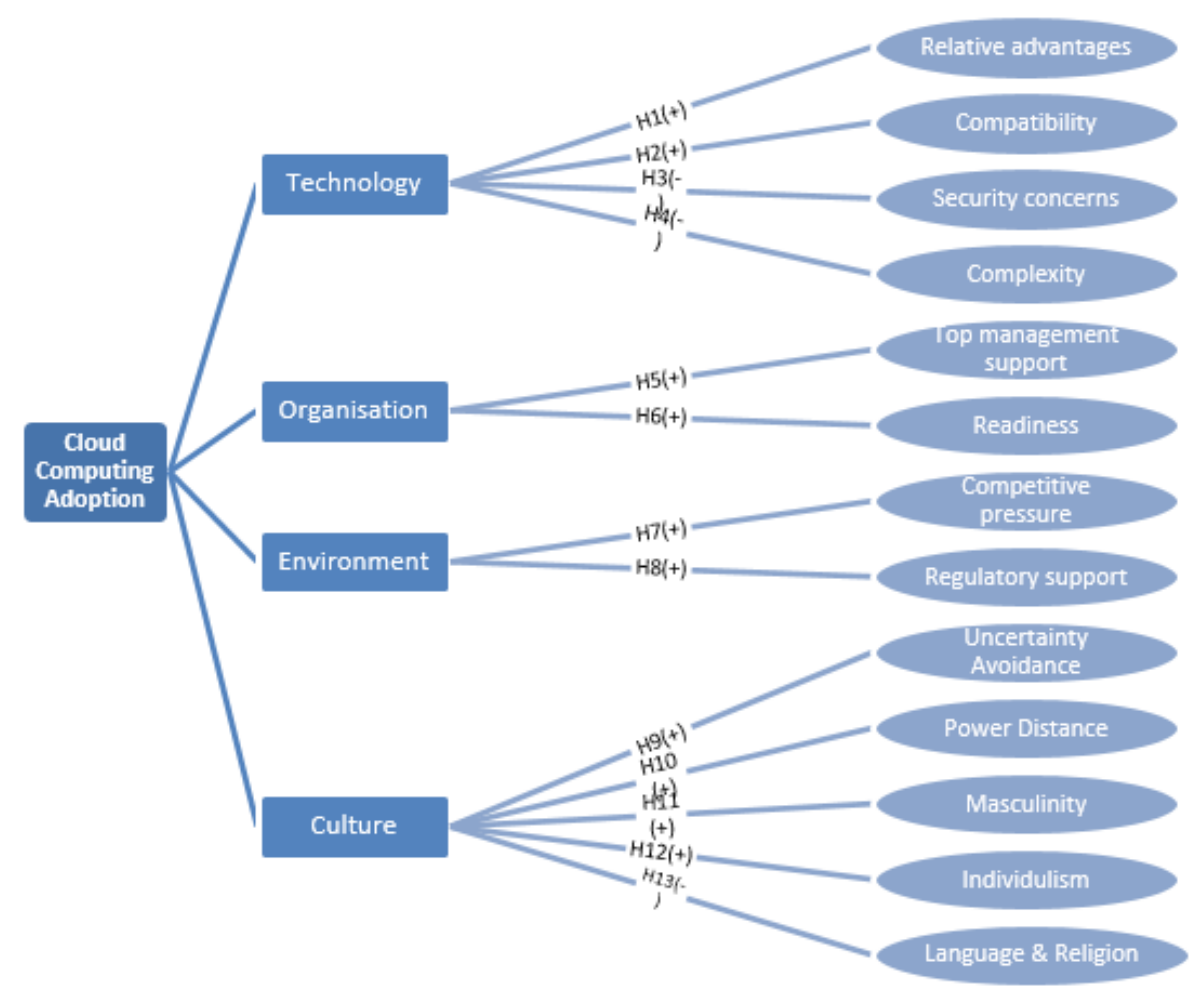

Figure 2. The refined model (after adding the new factors)

\subsection{Structural Equation Modelling (SEM)}

Structural equation modelling consists of two separate models: the measurement model and the structural model (Hair et al., 2010). The first one examines the relations between the latent variables and indicators. The structured model examines the relationships between the latent variables (unobserved variables) (Hox, 2010; Joseph F. Hair, Black, Babin, \& Anderson, 2010).

Measurement model. The measurement model is applied to evaluate the reliability and validity of the constructs before continuing with the structural model (Brown, 2014). In order to evaluate the contribution of each variable and assess the measurement model adequacy, confirmatory factor analysis (CFA) was conducted. Using AMOS 22.0, a CFA was conducted based on the results of survey data collected from the survey respondents.

CFA consists of three procedures. The first process is model specification. This requires defining the set of relationships which the researcher would like to check and deciding how to set the construct in the model. The second process is an iterative model modification process in order to evolve a foremost group of items to demonstrate a construct over the refinement and retesting process. Based on the previous process, items that do not meet reliability and validity assessment are dropped. The last process is estimating the goodness of fit (GOF) of the total model in order to check the degree to which the data support the measurement model.

After conducting confirmatory factor analysis (CFA), model fit determines the validity of each construct. Usually this assessment requires convergent and discriminant validity (Hair et al., 2006). Convergent validity asserts that the scale has a mutual relationship with other known measures of the concept. In this study, the convergent validity assessment emphasised the factor loading. Discriminant validity refers to the extent to which the measure is certainly new, and not just a throwback of other variables. For this study, discriminant validity could be evaluated by reviewing the correlation coefficient between each pair of variables.

The proposed measurement model. This study tested the proposed model's suitability to analyse the observed data using the bootstrap ML estimation techniques supplied by AMOS 22.0. The proposed model consisted of 13 latent variables of the proposed model using a number of items to approve the factor structure for the variables. An overall 48 items were utilized in the measurement model. These items were obtained from the literature.

The fit statistics and indices for the proposed measurement model are summed up in Table 2, while the proposed measurement model is illustrated in Figure 3. 
Table 2. GOF Indices for the proposed model

\begin{tabular}{lllllll}
\hline Measurement model & GFI & RMSEA & SRMR & CFI & TLI & x2/df \\
\hline Recommended & $>0.90$ & $<0.05$ & $\leq .08$ & $>0.90$ & $>0.90$ & $<3.0$ \\
Obtained & 0.910 & 0.013 & 0.0387 & 0.992 & 0.990 & 1.081 \\
\hline
\end{tabular}

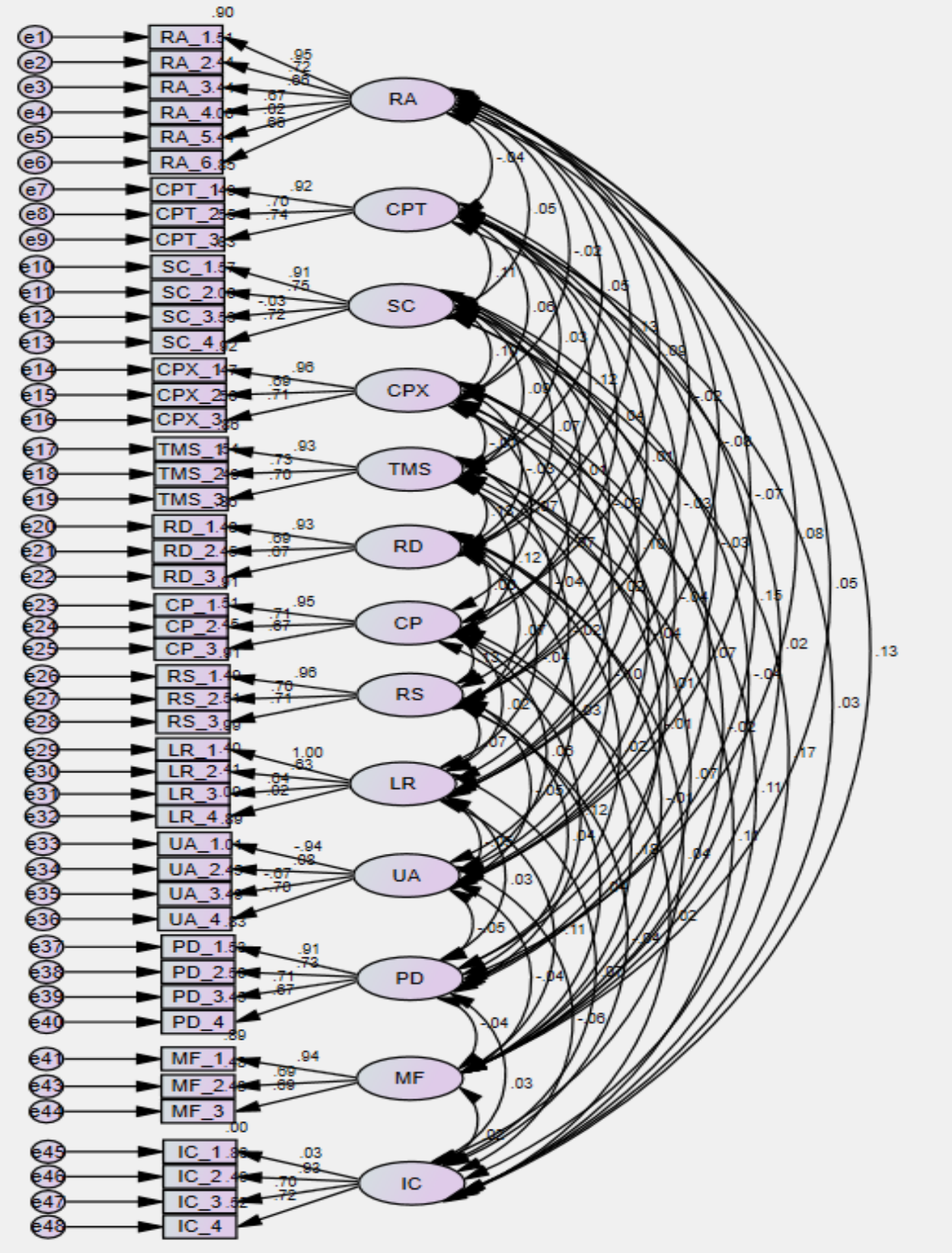

Figure 3. The proposed measurement model

As presented in Table 2, the model exhibited a good level of fit. All the indicators (factors) and significant loadings were greater than $0.50(\mathrm{p}<0.001)$ on their respective constructs. However, the factor loading of some items was less than 0.50 and the squared multiple correlation (SMC) was less than 0.30 , which means the coefficient paths of these items were insignificant (Byrne, 2010; Hair et al., 2010). Therefore, these items were eliminated from constructs in the revised measurement model in the next section.

The revised measurement model. A revised measurement model was established based on the assessment of factor 
loading and squared multiple correlation (SMC). This resulted in eliminating five items at the iterated convergent validity and reliability analysis stage since all the items with loading $<0.50$ and SMC $<0.30$ were dropped. The fit indices for the revised measurement model are summarised in Table 3 . The model exhibited a good level of fit

Table 3. Indices for the measurement model

\begin{tabular}{lllllll}
\hline Measurement model & GFI & RMSEA & SRMR & CFI & TLI & x2/df \\
\hline Proposed model & 0.910 & 0.013 & 0.0381 & 0.990 & 0.990 & 1.081 \\
Revised model & 0.917 & 0.012 & 0.036 & 0.992 & 0.990 & 1.064 \\
\hline
\end{tabular}

The structural model. Testing the structural model was the next step, following validation of the established measurement model. This was done by testing the hypothesised conceptual model. To test the hypothesis, a structural model with all 13 factors that were evaluated in the measurement model was developed. Subsequently, the hypothesised connections were framed between these constructs.

\section{Testing the hypotheses}

In order to construct the evaluated population covariance matrix for the structural model, the parameter estimates were applied. There were 13 constructs recognised by 46 items in the model. To examine the structural model, the covariance matrix between the constructs was stratified. Joseph F. Hair et al. (2010) have stated that if the critical ratio (C.R./t-value) is more than 1.96 for an assessment (regression weight), the parameter coefficient value is statistically significant at the 0.05 levels. The $t$-value was gained by dividing the regression weight assessment by the estimate of its standard error (S.E). Thirteen causal paths were inspected in this study by using the path estimates and CR values. Table 4 shows that 11 hypothesised paths were statistically significant while two hypothesised paths were statistically not significant.

Table 4. Path coefficients for the proposed structural model

\begin{tabular}{llllll}
\hline \multicolumn{2}{l}{ Path (Hypothesis) } & Standardised path coefficient & t-value & Hypothesis testing result \\
\hline RA & $\rightarrow$ & adop_int & 0.189 & $6.971^{* * *}$ & Supported \\
CPT & $\rightarrow$ & adop_int & 0.195 & $7.375^{* * *}$ & Supported \\
SC & $\rightarrow$ & adop_int & 0.108 & $4.746^{* * *}$ & Supported \\
CPX & $\rightarrow$ & adop_int & 0.031 & n.s & Not Supported \\
TMS & $\rightarrow$ & adop_int & 0.168 & $5.825^{* * *}$ & Supported \\
RD & $\rightarrow$ & adop_int & 0.107 & $4.537^{* * *}$ & Supported \\
RS & $\rightarrow$ & adop_int & 0.201 & $7.105^{* * *}$ & Supported \\
CP & $\rightarrow$ & adop_int & 0.172 & $5.746^{* * *}$ & Supported \\
LR & $\rightarrow$ & adop_int & -0.011 & n.s & Not Supported \\
UA & $\rightarrow$ & adop_int & 0.105 & $3.83^{* * *}$ & Supported \\
PD & $\rightarrow$ & adop_int & 0.191 & $7.923^{* * *}$ & Supported \\
MF $\rightarrow$ & adop_int & 0.142 & $6.442^{* * *}$ & Supported \\
IC & $\rightarrow$ & adop_int & 0.098 & $4.461^{* * *}$ & Supported
\end{tabular}

(***=significance at the 0.001 , n.s $=$ not significant $)$

\section{Findings and Discussion}

\subsection{Results of Testing the Research Hypotheses}

To investigate the critical determinants supporting the adoption of cloud computing in Saudi universities, a survey targeting senior management, IT managers and staff, and academics was used for data collection. An initial conceptual model, which was built on and extended the TOE theory via the inclusion of cultural factors, was tested and validated using SEM based on the survey data. Positive relationships between relative advantages, 
compatibility, senior management support, readiness, competitive pressure, regulatory support, masculinity and individualism and the adoption of cloud computing were identified. Moreover, negative relationships between cloud computing adoption and security concerns, uncertainty avoidance, and power distance were also identified. Complexity, language and religion were found to be insignificant in relation to the adoption of cloud computing.

\section{H1 Relative advantages of cloud computing positively influence the intention to adopt cloud computing.}

The qualitative and quantitative analysis found that the relative advantage conveyed by adopting cloud computing exerted a significant positive influence $(\beta=0.189, \mathrm{t}=6.971, \mathrm{p}<0.001)$. Therefore, the hypothesis is accepted.

Cloud computing decreases the cost of IT infrastructure maintenance and reduces the number of staff required. Furthermore, Saudi universities tend to outsource their computing from cloud computing providers in order that they can concentrate on other institutional goals. Moreover, analysis also uncovered the fact that the universities would consider the adoption of cloud computing if the latter were flexible and easy to use. This factor is significant and would have a positive effect on the adoption of cloud computing in Saudi universities.

\section{H2 Compatibility positively influences the intention to adopt cloud computing.}

In this study, compatibility referred to compatibility with current university work, existing hardware and software, and the university's IT strategy. The quantitative analysis of the data found that compatibility had the greatest impact on the adoption of cloud computing in the context of technology, demonstrating a significant positive influence $(\beta=0.195, \mathrm{t}=7.375, \mathrm{p}<0.001)$. Therefore, the hypothesis is accepted.

Data analysis indicated that Saudi universities are more willing to adopt cloud computing because they perceive it as being consistent with their potential needs and their work context without the need to make huge changes to accommodate its use. Universities where administrations want to use cloud technology should take initiatives to change existing processes to enhance the compatibility of cloud solutions with their existing infrastructure and working environment. Cloud computing should also be compatible with the universities' policies, IT development environment, and work needs (Lin \& Chen, 2012).

\section{H3 Security concerns negatively influence the intention to adopt cloud computing.}

In this study, security concerns related to protection from unauthorised access, data loss, losing control, and intellectual property theft. The quantitative analysis of the data found that security concerns about the storage of data in the cloud had the greatest single negative influence in relation to the adoption of the technology $(\beta=$ $0.108, \mathrm{t}=4.746, \mathrm{p}<0.001$ ).

\section{Therefore, the hypothesis is accepted.}

In this study, the participating IT managers declared that security concerns could be solved by advanced and up-to-date equipment and systems. On the other hand, it found that this factor was viewed differently according to the participant's type of responsibility. As an example, senior managers considered security concerns to be a serious challenge and they rated this at the top of their list of priorities, while IT staff demonstrated a greater understanding of the issues, and the flexibility to handle the challenge.

\section{H4 Complexity negatively influences the intention to adopt cloud computing.}

In this study, complexity encompassed the required skills, the need for the integration of cloud IT into the existing landscape, and the mental effort necessary to appreciate the concept of cloud computing. The quantitative analysis of the data found that complexity had the no impact on the adoption of cloud computing. ( $\beta$ $=0.031, \mathrm{t}=1.194)$; the complexity was non-significant. Therefore, the hypothesis is not accepted.

One possible reason complexity proved to be non-significant in this study is the variety of cloud computing services and resources available, none of which need significant technical changes to be incorporated into present systems, for example, cloud-based email systems from companies such as Google and Microsoft. In addition, most of the potential cloud computing participants already have the ICT skills needed to deal with the features of the cloud, and use some cloud computing services already through friendly user interfaces. They would not, therefore, have the burden of transferring or set up the systems. Moreover, the participants expected to receive intensive training before starting to use the new technology.

\section{H5 Top management support positively influences the intention to adopt cloud computing.}

In this study, top management support refers to the support of senior managers for adoption, having a clear strategy, and offering training courses. The quantitative analysis of the data found that this sort of support and encouragement exerted a significant positive influence on cloud computing adoption $(\beta=0.168, t=5.825, p$ 


\section{$<0.001)$. Therefore, the hypothesis is accepted.}

It was explicit in the findings that a positive attitude among senior managers positively influenced the adoption of cloud computing in their institutions. The greater the understanding of cloud computing among the leadership of the university, the more committed they are likely to be, and the greater the support for cloud adoption and the chances of developing a clear strategy, and offering training courses for cloud computing end users. Training staffs allows them to comprehend the practical and technical perceptions of cloud computing. They will be educated, responsible, and well informed for the effective use of cloud computing technologies, which become easier for them to use. Furthermore, they can appreciate the relevance of ICT in their job performance.

\section{H6 Organisational readiness positively influences the intention to adopt cloud computing.}

In this study, organisational readiness referred to the availability of necessary skills, convenient wireless Internet access, and Internet-enabled computers. The quantitative analysis of the data found that organisational readiness has a significant positive influence on cloud computing adoption $(\beta=0.107, \mathrm{t}=4.537, \mathrm{p}<0.001)$. Therefore, the hypothesis is accepted.

The findings emphasise the importance of having a suitable ICT platform in advance of adopting cloud computing. The findings indicate that those universities with higher levels of organisational readiness for cloud computing are more likely to use cloud computing services.

Thus, senior management needs to focus on technological resources, such as physical infrastructure and IT-educated staff. Moreover, management plays a critical role in motivating the employees by facilitating and developing the working environment. This could be done by providing the necessary resources, such as allocating time and updated equipment. In addition, it is critical that senior managers realise the role of technology in improving organisational performance and overcoming perceived performance gaps (Gangwar, Date, \& Ramaswamy, 2015).

\section{H7 Competitive pressure from competitors positively influences the intention to adopt cloud computing.}

In this study, competitive pressure includes the adoption of cloud computing by the majority of competitors, the intention to adopt cloud computing by the competitors, and recommendations by the government. Competitive pressure has a significant positive influence on cloud computing adoption $(\beta=0.172, t=5.746, p<0.001)$. Therefore, the hypothesis is accepted.

The significance of competitive pressure to the adoption of cloud computing reveals that Saudi universities are prone to adopt cloud computing in order to maintain their competitive position. Moreover, the wish of the Saudi Ministry of Education to upgrade the education level, especially at universities, exerts considerable pressure on universities to adopt cloud computing.

\section{H8 Regulatory support positively influences the intention to adopt cloud computing.}

In this study, regulatory support referred to regulations to protect the users, laws regarding data ownership and responsibility, and budgetary sufficiency. Regulatory support has a significant positive influence on cloud computing adoption $(\beta=0.201, \mathrm{t}=7.105, \mathrm{p}<0.001)$. Therefore, the hypothesis is accepted.

The significance of regulatory support to the adoption of cloud computing reveals that the assistance from the Saudi government through the development of policies, programs, and budgetary provision has given rise to an educational renaissance that is potentially facilitative of the adoption process. It was noticed from the interview analysis that the government support would aid the organisations to beat any financial shortage. However, the lack of known policies and regulation have all reduced the progress and adoption of cloud computing in the education sector in Saudi.

\section{H9 High uncertainty avoidance negatively influences the intention to adopt cloud computing.}

Quantitative analysis of the data found that high uncertainty avoidance has a negative impact on cloud computing adoption, and the impact is significant $(\beta=0.105, \mathrm{t}=3.83, \mathrm{p}<0.001)$. Therefore, the hypothesis is accepted.

As is the case with power distance, societies with high uncertainty avoidance scores record lower adoption rates of technology than societies with low uncertainty avoidance scores. This is because people in countries with a high score for uncertainty avoidance are more risk unwilling and resist doing things for the first time. Adoption of any innovation that is proposed is likely to be influenced by uncertainty avoidance

Saudi scores 80 on this dimension and displays a preference for avoiding uncertainty, as confirmed by qualitative and quantitative analysis. The high UA score from Saudi universities suggests that the decision makers in the 
universities are not risk takers when dealing with IT projects. For some of them, new technologies are something 'unknown' and there are no particular results expected that they can rely on, so they may choose to avoid risks and avoid investing in these projects.

Those who are uncertainty avoidant prefer having formal rules and measured outcomes that insure positive results. In the IT world, where technologies change rapidly, the effects are unknown and the potential for unintended consequences are great; uncertainty is to be expected. So, managers may need to decrease the uncertainty attaching to ICT by, for example, clearly stating the advantages of the new technology and emphasizing the new ideas adoption requires.

\section{H10 High power distance negatively influences the intention to adopt cloud computing.}

The quantitative analysis of the data found that a high power distance has a negative impact on cloud computing adoption. Power distance has the greatest significant impact of all the factors $(\beta=0.191, t=7.923, p<0.001)$. Therefore, the hypothesis is accepted.

There is evidence that a larger power distance often results in a lack of communication and collaboration among individuals, whether in the same organisation or in different organisations (Abdulrab, 2011). Saudi scores high in power distance (score of 95/100), having a hierarchical culture in which everybody has a place, and which needs no additional justification, as indicated by the quantitative and qualitative analysis. So, it is recommended that managers try to minimize the power distance between themselves and their employees in order to increase ICT adoption chances.

Another implication of a high power distance index (PDI) in universities is the lack of technological knowledge and the end users' needs. It is reasonable to encourage an organisational culture within which employees can express their ideas freely, without considering their status difference. Otherwise, important ideas coming out at the bottom level may die-off without having a chance for expression or implementation (Erumban \& De Jong, 2006).

Hofstede's original study in 1980 indicated that the Arab World region, which includes Egypt, Iraq, Kuwait, Saudi, the United Arab Emirates, Lebanon, and Libya had a PDI of 80, compared to a PDI of 40 for the United States, a high-technology-adopting country (Abdulrab, 2011).

\section{H11 High masculinity positively influences the intention to adopt cloud computing.}

The quantitative analysis of the data found that high levels of masculinity have a positive impact on cloud computing adoption $(\beta=0.142, t=6.442, p<0.001)$. Therefore, the hypothesis is accepted.

The MAS index indicates the distribution of roles between genders in a culture. High MAS score cultures represent masculine cultures where social gender roles are distinguished: men have to be firm and concentrated on physical success, and women are expected to be more shy and interested in the life quality improvement. Low MAS score cultures represent feminine cultures where social gender roles can be mixed, with both males and females encouraged to be modest, nurturing, and interested in the quality of life (Abdulrab, 2011).

Saudi scores 60 for this dimension and is therefore a 'masculine' society. In masculine countries people 'live to work'; managers are expected to be firm and confident; the stress is on justice, competition and performance.

According to Hofstede (1991), organisations in masculine cultures place special importance on rewards and acknowledgement of performance, in addition to training and self-improvement.

\section{H12 High individualism positively influences the intention to adopt cloud computing.}

The quantitative analysis of the data found that high levels of individualism have a positive impact on cloud computing adoption, and exercised significant impact $(\beta=0.098, \mathrm{t}=4.461, \mathrm{p}<0.001)$. Therefore, the hypothesis is accepted.

People in countries that emphasise individualism in their culture expect people to make their own choices and to take care of themselves and their close family only, while people in countries with a culture of collectivism belong more strongly to groups that take care of them in exchange for sincerity. Persons in individualistic countries have the ability to express their own views freely and are consequently more prepared to innovate and adopt new ideas (Erumban \& De Jong, 2006).

Saudi, with a score of $25 / 100$, is considered a collectivistic or communal society. Arab culture in general is known for being a collectivistic culture in which people tend to consider themselves as groups members, such as families or tribes, and generally think the group's needs are more important than the individual's needs. Within this tribal Arab culture, the group have priority over the individual. The value of the group comes first and the 
responsibility falls on the whole group instead of specific individual. Saudi may possibly be one of the most collectivistic cultures among other Arab cultures, because of the strong tribal system that is still very apparent in the country.

\section{H13 Language and religion negatively influence the intention to adopt cloud computing.}

The quantitative analysis of the data found that language and religion have a non-significant impact $(\beta=-0.011$, $\mathrm{t}=-0.523)$. Therefore, the hypothesis is rejected.

English will certainly impact the advantage ICT presents as noted by Maitland and Bauer (2001). Maitland and Bauer have pointed out that English language ability is a cultural variable related specifically to Internet adoption. Grazzi and Vergara (2012) have added that familiarity with the English language, which is commonly used in ICT, is generally low and extremely concentrated in well-educated and wealthy groups in Saudi. In this study, language was not found to be a barrier, possibly because the participants in this study were well-educated people with a good knowledge of computers.

Regarding religion, the study found that religion exerted no significant impact on the adoption of cloud computing. This result concurs with Tanasyuk and Avgerou (2009), who found that the religious community of Athos recognise ICTs as useful for them in terms of data storage and time saving, and they did not find ICT incompatible to their spiritual goals.

On the other hand, Kalliny and Hausman (2007) argue that some of the main religions, such as Islam and Christianity, can affect some innovation adoption strongly. They reckon that the innovation producers can modify their product to suit the country's culture. They recommend that in societies where religion and government have the strongest authority (such as Saudi, Egypt and Lebanon), the inno vation producer could approach the authorised people and receive their approval before introducing an innovation.

Moreover, Sanaktekin, Aslanbay, and Gorgulu (2013) found that religion has a significant effect on Internet consumption, and, as religiosity increases, Internet consumption decreases. Most religious people doubt and resist using the Internet. Campbell (2011) researched religion and the Internet within the Israeli context. The study showed that although the Internet is utilised, it is still regarding doubtfully.

\section{Research Conclusion}

In summary, the following factors were found that encourage cloud computing adoption in Saudi universities: relative advantages, compatibility, top management support, organisational readiness, competitive pressure, regulatory support, high individualism and high masculinity.

The following factors were found to discourage the adoption of cloud computing in Saudi universities: security concerns, high power distance and high uncertainty avoidance.

Complexity and language and religion were found to have no impact on the adoption of cloud computing.

\section{Future Research}

Future research can add to this study by examining the adoption phase of cloud computing in Saudi universities, including investigating differences in the adoption between the main and small cities. Moreover, significant factors in other countries by applying this research will be a good addition. Additionally, future research can pay attention to the implementation process and the influences of cloud computing on university production to get a comprehensive perception of cloud computing.

\section{References}

Abdulrab, S. (2011). The impact of culture on information technology adoption in Yemeni universities. PhD Thesis. Robert Morris University. Moon Township, PA, USA. ProQuest Dissertations and Theses

Al-Gahtani, S. S., Hubona, G. S., \& Wang, J. (2007). Information technology (IT) in Saudi Arabia: Culture and the acceptance and use of IT. Information \& Management, 44(8), 681-691. https://doi.org/10.1016/j.im.2007.09.002

Alkhater, N., Wills, G., \& Walters, R. (2014). Factors influencing an organisation's intention to adopt cloud computing in Saudi Arabia. Paper presented at the Cloud Computing Technology and Science (CloudCom), 2014 IEEE 6th International Conference on Cloud Computing Technology and Science. https://doi.org/10.1109/CloudCom.2014.95

Alsanea, M. (2015). Factors affecting the adoption of cloud computing in Saudi Arabia's government sector. Doctoral thesis. Goldsmiths, University of London. https://doi.org/10.11591/closer.v3i6.6811 
Altshuler, A., \& Zegans, M. (1990). Innovation and creativity: Comparisons between public management and private enterprise. Cities, 7(1), 16-24. https://doi.org/10.1016/0264-2751(90)90003-P

Brown, T. A. (2015). Confirmatory factor analysis for applied research. $2^{\text {nd }}$ ed. New York: Guilford Press.

Campbell, H. (2011). Religion and the internet in the Israeli Orthodox context. Israel Affairs, 17(3), 364-383. https://doi.org/10.1080/13537121.2011.584664

Chieochan, O., Lindley, D., \& Dunn, T. (2003). The adoption of information technology: A foundation of e-commerce development in Thai culture. In E-commerce and cultural values, 17-50. https://doi.org/10.4018/978-1-59140-056-1.ch002.

Erumban, A. A., \& De Jong, S. B. (2006). Cross-country differences in ICT adoption: A consequence of culture? Journal of World Business, 41(4), 302-314. https://doi.org/10.1016/j.jwb.2006.08.005

Gangwar, H., Date, H., \& Ramaswamy, R. (2015). Understanding determinants of cloud computing adoption using an integrated TAM-TOE model. Journal of Enterprise Information Management, 28(1), 107-130. https://doi.org/10.1108/JEIM-08-2013-0065

Grazzi, M., \& Vergara, S. (2012). ICT in developing countries: Are language barriers relevant? Evidence from

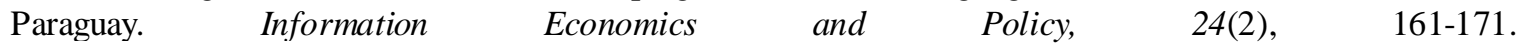
https://doi.org/10.1016/j.infoecopol.2011.11.001

Hill, C. E., Loch, K. D., Straub, D. W., \& El-Sheshai, K. (1998). A qualitative assessment of Arab culture and information technology transfer. Journal of Global Information Management, (6), 29-38. https://doi.org/10.4018/jgim.1998070103

Hofstede, G. (1991). Cultures and organisations-software of the mind. McGraw-Hill. https://doi.org/10.1016/0147-1767(92)90033-Q

Hofstede, G. (2001). Culture's consequences: Comparing values, behaviors, institutions and organizations across nations. SAGE.

Hox, J. (2010). Multilevel analysis: Techniques and applications. Routledge.

Ibrahim, M. S., Salleh, N., \& Misra, S. (2015). Empirical studies of cloud computing in education: A systematic literature review. Paper presented at the International Conference on Computational Science and Its Applications (ICCSA) 2015, 725-737. https://doi.org/10.1007/978-3-319-21410-8_55

Joseph F. Hair, J., Black, W. C., Babin, B. J., \& Anderson, R. E. (2010). Multivariate data analysis. ( th $^{\text {th }}$ ed.). Hair, Anderson, Black \& Babin.

Kalliny, M., \& Hausman, A. (2007). The impact of cultural and religious values on consumer's adoption of innovation. Academy of Marketing Studies Journal, 11(1), 125.

Lin, A., \& Chen, N.-C. (2012). Cloud computing as an innovation: Perception, attitude, and adoption. $\begin{array}{llll}\text { International Journal of Information } & \text { Management, 32(6), }\end{array}$ https://doi.org/10.1016/j.ijinfomgt.2012.04.001

Maitland, C. F., \& Bauer, J. M. (2001). National level culture and global diffusion: The case of the Internet. In Culture, technology, communication: Towards an intercultural global village, 87-128.

Mell, P., \& Grance, T. (2011). The NIST definition of cloud computing, 15. Gaithersburg: National Institute of Standards and Technology. https://doi.org/10.6028/NIST.SP.800-145

Perry, J. T., \& Schneider, G. P. (2000). New perspectives on e-commerce: Introductory. Course Technology Ptr.

Rogers Everett, M. (1995). Diffusion of innovations. The Free Press, New York.

Sanaktekin, O. H., Aslanbay, Y., \& Gorgulu, V. (2013). The effects of religiosity on internet consumption: A study on a Muslim country. Information Communication \& Society, 16(10), 1553-1573. https://doi.org/10.1080/1369118X.2012.722663.

Slowikowski, S., \& Jarratt, D. G. (1997). The impact of culture on the adoption of high technology products. Marketing Intelligence \& Planning, 15(2), 97-105. https://doi.org/10.1108/eb010276.

Tanasyuk, P., \& Avgerou, C. (2009). ICT and religious tradition: the case of Mount Athos. Paper presented at the IFIP WG9.4 Conference, Dubai, UAE. Retrieved from http://eprints.lse.ac.uk/35560/

Tashkandi, A., \& Al-Jabri, I. (2015). Cloud computing adoption by higher education institutions in Saudi Arabia: Analysis based on TOE. Paper presented at the 2015 International Conference on Cloud Computing (ICCC). 
https://doi.org/10.1109/CLOUDCOMP.2015.7149634.

Vatanasakdakul, S., Tibben, W., \& Cooper, J. (2004). What prevent B2B eCommerce adoption in developing countries?: a socio-cultural perspective. Paper presented at the 17th Bled eCommerce Conference on eGlobal. Retrieved from http://aisel.aisnet.org/bled2004/52

Venkatesh, V., Morris, M. G., Davis, G. B., \& Davis, F. D. (2003). User acceptance of information technology: Toward a unified view. MIS Quarterly, 425-478. Retrieved from http://www.jstor.org/stable/30036540

Weber, A. S. (2011). Cloud computing in education in the Middle East and North Africa (MENA) region: Can barriers be overcome? eLearning and Software for Education(eLSE) Journal, 2011, (1).

\section{Copyrights}

Copyright for this article is retained by the author(s), with first publication rights granted to the journal.

This is an open-access article distributed under the terms and conditions of the Creative Commons Attribution license (http://creativecommons.org/licenses/by/4.0/). 